\title{
Developing an Asynchronous Online Tennessee Master Nursery Producer Program
}

\author{
S. Christopher Marble ${ }^{1,4}$, Amy Fulcher ${ }^{2,5,7}$, and Richard Karel ${ }^{3,6}$
}

ADDITIONAL INDEX WORDs. continuing education, nursery production, ornamental, professional development, woody crops

SUMMARY. Asynchronous online extension classes, in which content is made available on demand, can reach a larger audience, offer more scheduling flexibility, and reduce the strain on limited time and financial resources for extension faculty and staff. In comparison with traditional extension programming (in-person presentations) or online synchronous programming (live webinars), asynchronous programs can require significant time and resources during the initial development stages, including advanced planning and dedicated contributors as well as ongoing information technology (IT) infrastructure and maintenance. The objective of this article is to summarize the development process and inputs needed to successfully develop an online asynchronous extension program based on the authors' experience developing the Tennessee Master Nursery Producer Program (TMNP). The TMNP is a certificate program for nursery growers in Tennessee designed to improve growers' long-term environmental, economic, and community sustainability. Developing the online TMNP required three key positions: project coordinator, e-learning specialist, and content developer which spent 473, 401, and 847 hours, respectively, during the development process. Detailed information on development time, requirements, and suggestions for other institutions wishing to develop similar programs is offered.

$\mathrm{T}$ he traditional extension education model, in which staff administers in-person presentations that growers in a particular region of the state attend, has proven successful in the past (Jones et al., 2007). Although effective, this model

This paper results from the workshop "Online Learning and Big Data in Horticulture: New Insights and Directions" held on 4 Aug. 2015 at the ASHS Conference, New Orleans, LA, and sponsored by the Computer Applications in Horticulture (COMP) Working Group.

Jim Brosnan and Gary Knox are gratefully acknowledged for reviewing an internal draft of the manuscript. We thank the Tennessee Department of Agriculture for financial support to develop the Tennessee Master Nursery Producer Program and Whitney Yeary for technical assistance.

Mention of a trademark, proprietary product, or vendor does not constitute a guarantee or warranty of the product by the authors or their respective institutions and does not imply their approval to the exclusion of other products or vendors that may also be suitable.

${ }^{1}$ Department of Environmental Horticulture, University of Florida, Mid-Florida Research and Education Center, 2725 South Binion Road, Apopka, FL 32703

${ }^{2}$ Department of Plant Sciences, University of Tennessee, 2431 Joe Johnson Drive, Ellington Plant Science Building, Room 252, Knoxville, TN 37996

${ }^{3}$ Office of Information Technology, University of Tennessee, Metron Center Way, Knoxville, TN 37919

${ }^{4}$ Former postdoctoral scholar, University of Tennessee

${ }^{5}$ Associate professor

${ }^{6}$ Instructional technology specialist

${ }^{7}$ Corresponding author. E-mail: afulcher@utk.edu.

doi: 10.21273/HORTTECH03341-16 can pose challenges for the audience, particularly so for nursery crop producers. The need for growers to leave their daily activities and varying production schedules makes it difficult to select a time when all industry members can be present. Traditional programs are also associated with substantial travel costs and a great ongoing time commitment of faculty, staff, and participants. In recent years, extension budgets have decreased, limiting both faculty positions and their travel support.

The Internet is the fastestgrowing platform for formal education (Allen and Seaman, 2011; Haynie, 2015) and is becoming a preferred method for informal education (Dittman Research and Communications Corp., 2010; Rich et al., 2011). Online distance education programs have the potential to be more time efficient and inexpensive compared with traditional programs due to economies of scale (Sagor et al., 2014; The Economist, 2014), and reach a larger audience regardless of their location. Furthermore, online continuing education programs have proven to be an effective way to reach green-industry professionals (VanDerZanden, 2013a, 2013b).

Online classes can either be synchronous or asynchronous. Synchronous classes are live webinars delivered in real time and have been implemented successfully for some forestry extension programs (Allred and Smallidge, 2010) and for the green industry (Vergot et al., 2014). Synchronous programs are popular because they offer real-time communication between the audience and the speaker, which provides a more traditional classroom experience, and require little infrastructure, presentation preparation beyond live classroom presentation, or program maintenance. Asynchronous programs, in which the participants $\log$ in and take the program at their own pace, are less common than synchronous programs, in part because they are more complex to produce and require more planning and a greater time commitment upfront (Zobrist, 2014). However, asynchronous online programs provide benefits for both extension personnel and course participants. Growers have access to the content from their home or office and can view course materials at their convenience. Like a flipped classroom (Herreid and Schiller, 2013), participants can view more challenging content as many times as needed to master the concept. Asynchronous programs are completed in advance of publishing online and the instructor need not be present when materials are viewed by students. Thus, the instructor schedule is unaffected by program dates as with a traditional program. In addition, online learning management software can automatically compile survey and questionnaire responses and tests taken by program participants. For a comparison of asynchronous and traditional programs, please consult the companion article by Marble et al. (2016).

The University of Tennessee, in collaboration with partners at the U.S. Department of Agriculture and Tennessee State University, developed an asynchronous education program for nursery producers entitled "Tennessee Master Nursery Producer Program" (Fulcher et al., 2014) (Fig. 1). This program was created due to grower interest in a comprehensive educational series covering the many aspects of nursery crop production. The TMNP was designed to provide Tennessee nursery producers with the best information possible to enhance their profitability and long-term environmental, economic, and community 


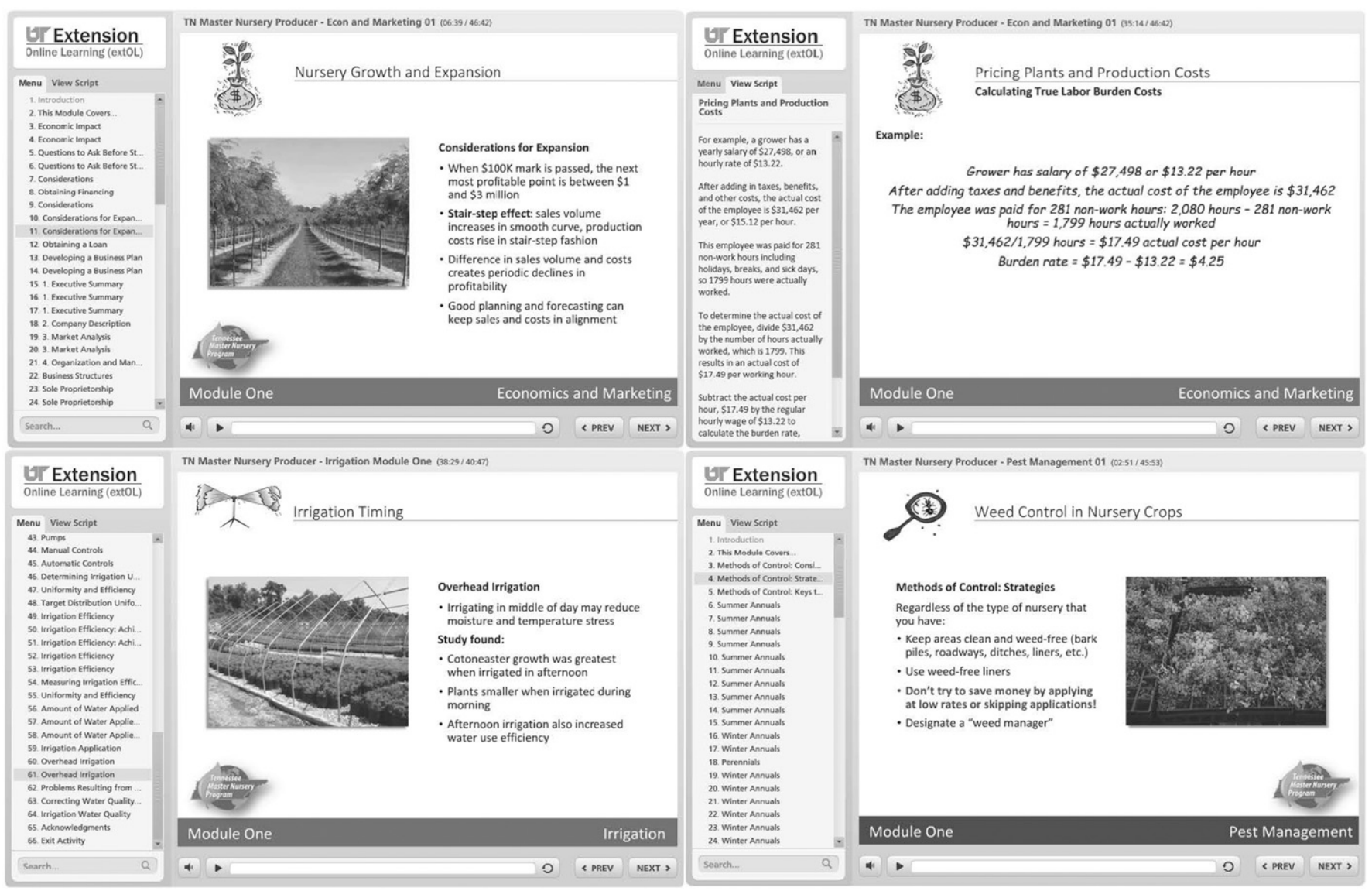

Fig. 1. Examples of Tennessee Master Nursery Producer Program online learning module interface.

sustainability. Growers who successfully complete the program are certified as Tennessee Master Nursery Producers, and can receive greater cost-share opportunities through the Tennessee Agricultural Enhancement Program, which provides cost-share funds to qualified growers in the state for approved business enhancement projects and expenses (Tennessee Department of Agriculture, 2015). Growers from other states may also take the course, but do not qualify for cost-share funds.

The TMNP was first designed as a traditional face-to-face extension program. Numerous seminars were presented to live, in-person audiences for $4 \mathrm{~h}$ per week for 6 weeks in Fall 2012 with the inaugural class of 45 growers graduating in Jan. 2013. Participants estimated they saved $\$ 4272$ per graduate in the year after graduation as a result of information gained and practices changed. On the basis of grower feedback and economic impact, this course was successful, but it required a significant time commitment from faculty and staff. In addition, out-of-state experts were relied upon which required substantial financial resources and represented a significant ongoing expense. Participants also had to travel to attend the course each week, and those in locations distant from the course site were fettered by scheduling conflicts and/or the distance and expense of traveling overnight. Therefore, an asynchronous course was developed in 2013 to help mitigate these problems, maximize the economies of scale, increase availability across the state, and standardize content from class to class.

There is minimal information available to institutions concerning the staff requirements and other necessary resources needed for developing online programs for producers. Therefore, the objective of this paper is to use the development of the TMNP as a case study to present the resources needed and the overall process of successfully developing an asynchronous online educational program and to provide insights to other institutions wishing to develop similar programming.

\section{Materials and methods}

Personnel. The key roles for the TMNP were a committee, project coordinator, a curriculum developer, two narrators, and an IT professional with expertise in electronic instructional design (e-learning systems designer). The TMNP committee consisted of county extension agents, regional extension specialists, government scientists, and university professors currently employed in Tennessee who had close ties with the industry. Committee members worked together to identify appropriate funding and inform course material based on their areas of expertise and to address relevant industry issues. The project coordinator made a detailed outline of program content, coordinated content development, narration, and IT activities, and provided editing and quality control. The curriculum developer prepared program content, which 
consisted of conducting literature reviews, preparing slides (text and images), drafting scripts, and creating quizzes for each module. After scripts were ended, they were recorded by a narrator. The e-learning systems rendered the content for online delivery.

Initially, the e-learning systems designer and the project coordinator met to review the purpose of the program and examine the complexities of online programming. The e-learning systems designer then designed the modules (storyboard template), so that the content was delivered in a consistent format and so that the design ensured content presentation was suitable for online delivery and would facilitate learning. The e-learning systems designer created quizzes and questionnaires from prepared content, created bullet point animation, synchronized narration with animation within the storyboard template, as well as provided sound/audio expertise for rendering narration audio files. The e-learning systems designer also managed all aspects of making the content available online and ensuring that access to content was controlled so that participants had access to each module of the program in the proper sequence.

A dedicated curriculum developer was beneficial because it allowed for consistency across the modules and a significant amount of time could be devoted to literature searches, image selection, and script development. A dedicated curriculum developer also allowed the project to stay on schedule and avoided conflicting responsibilities, which would have been a potential complication had a faculty member taken on this responsibility or even if multiple faculty members divided the responsibility. A critical requirement for the curriculum developer was in-depth, yet broad knowledge of nursery production. In this case, the curriculum developer was a postdoctoral scholar with nursery production expertise.

Content Development. For the TMNP, the TMNP committee identified broad topics based on their expertise that addressed relevant industry issues. After the subject matter was selected, it was organized into an outline for content development. To keep all modules under $60 \mathrm{~min}$, several of the eight subject areas were broken down into multiple modules. The eight major subject areas and the number of modules for each subject (listed parenthetically) included container production (4), field production (3), plant nutrition and fertilizer use (1), irrigation management (2), pest management (5), pruning (1), propagation (2), and economics and marketing (3).

Module preparation began each week by conducting a thorough literature review to gather the most relevant and current information available on each subject. Images were selected from a collection of digital images that were taken previously by the project team and organized into an electronic file for each module, taking into consideration that an instructor would not be present to highlight important aspects of each photo. In many cases, photos had to be cropped and edited to clearly illustrate teaching points. When no pertinent image was available in the database, other faculty, staff, or extension agents were asked for permission to use their photos and were given photo credits for their work in each module. An important aspect to online program development is that image use will come under much greater scrutiny when publishing online compared with a live presentation. In many cases, images that had been used to give live presentations could not be used in the online modules due to permission or copyright issues.

After image selection and organization, PowerPoint (Microsoft Corp., Redmond, WA) slides were created according to the course outline and available literature by making bullet points for the main learning objectives of each slide and adding one image per slide. Each module consisted of roughly 60 to 80 slides, with a goal of keeping narration for each slide at $1 \mathrm{~min}$ or less and total module length at $60 \mathrm{~min}$. The subject matter of each slide dictated how long the slide would take to narrate and consequently the number of slides for each module. For example, the weed control module contained information on herbicides that are commonly used in nursery production, and in many cases, an individual slide focused on one herbicide. In this case, narration was minimal (covering only usage rates, crops, special precautions, etc.), and thus, more slides were used to create a 60 -min module. For more complicated topics, such as testing irrigation efficiency, more narration was needed for a particular slide causing it to slightly exceed the 1-min mark, or requiring development of additional slides to present the concept as a step-by-step set of instructions.

The final step of content development was the creation of a script for each module. Scripts were originally developed using word processing software, one file per module. Script content for each slide was developed from personal knowledge and experience, communication with industry and academia, scientific publications, extension literature, and trade journals or similar publications (price lists, catalogs, etc.). To emphasize the main points and facilitate learning, the script was written in the same order and with nearly identical or identical phrasing as the slide bullet points that comprised the main learning objectives of each slide, and with concise, straightforward language whenever possible (Bean, 2014). After initial editing by the program coordinator and curriculum developer was complete, the script was pasted into the notes section of each slide.

After slides and the script were completed, they were reviewed by the project coordinator for content, accuracy, grammar, and sentence structure. Subject matter experts (one per module) were asked to review modules for accuracy and content when the developer or coordinator did not have expertise in a particular area, or it was subject matter that was evolving (i.e., pest quarantine laws and regulations). Each module, consisting of the PowerPoint, script, and quiz, was checked a final time for accuracy and errors by the project coordinator and the content developer to end technical material and approve image substitutions.

Adopting finAL STORYBOARD, NARRATION PROCESS, AND QUALITY CONTROL. The project coordinator and curriculum developer initially took on all developmental responsibilities, including graphic design, temporary storyboard creation (populated the PowerPoint with content), technical editing, and graphics creation, in addition to curriculum 
Table 1. Time needed to develop initial PowerPoint (Microsoft Corp., Redmond, WA) and script for Tennessee Master Nursery Producer Program.

\begin{tabular}{|c|c|c|c|c|c|c|}
\hline \multirow[b]{2}{*}{ Subject $^{\mathrm{z}}$} & \multirow[b]{2}{*}{ Subcategory $^{\mathrm{y}}$} & $\begin{array}{c}\text { Research/content } \\
\text { development }{ }^{\mathrm{x}}\end{array}$ & $\begin{array}{l}\text { PowerPoint } \\
\text { development }^{\mathrm{w}}\end{array}$ & $\begin{array}{c}\text { Image } \\
\text { organization }^{\mathrm{v}}\end{array}$ & $\begin{array}{c}\text { Script/quiz } \\
\text { development }\end{array}$ & $\begin{array}{l}\text { Total time } \\
\text { per module }\end{array}$ \\
\hline & & \multicolumn{5}{|c|}{ Time (h) } \\
\hline General & $\begin{array}{l}\text { Overall content outline, } \\
\text { quizzes and questionnaires }\end{array}$ & 31.25 & $\mathrm{NA}^{\mathrm{t}}$ & NA & NA & 31.25 \\
\hline \multirow{2}{*}{$\begin{array}{l}\text { Container } \\
\text { production }\end{array}$} & General facilities & 15.75 & 8.0 & 8.0 & 12.0 & 43.75 \\
\hline & Overwintering & 15.75 & 8.0 & 6.0 & 12.0 & 41.75 \\
\hline \multirow{3}{*}{$\begin{array}{l}\text { Field } \\
\text { production }\end{array}$} & General facilities & 7.5 & 8.0 & 8.0 & 12.0 & 35.5 \\
\hline & Layout; cover crops; planting & 11.25 & 8.0 & 6.5 & 12.0 & 37.75 \\
\hline & ANLA $^{s}$ standards; harvesting & 8.5 & 8.0 & 6.0 & 11.0 & 33.5 \\
\hline \multirow{2}{*}{$\begin{array}{l}\text { Pest } \\
\text { management }\end{array}$} & Weed control & 7.5 & 10.0 & 9.5 & 13.5 & 40.5 \\
\hline & Insect control & 11.5 & 8.0 & 6.0 & 12.0 & 37.5 \\
\hline Plant nutrition & Plant nutrition and fertilizer & 9.0 & 8.0 & 6.0 & 12.0 & 35.0 \\
\hline \multirow{2}{*}{ Irrigation } & Delivery; scheduling & 9.0 & 8.5 & 6.0 & 12.5 & 36.0 \\
\hline & Capturing and reusing & 9.0 & 8.5 & 5.0 & 12.0 & 34.5 \\
\hline Pruning & Pruning & 17.25 & 8.0 & 6.0 & 12.0 & 43.25 \\
\hline \multirow[t]{2}{*}{ Propagation } & Seed & 8.5 & 10.0 & 6.0 & 12.0 & 36.5 \\
\hline & Vegetative & 14.75 & 10.0 & 6.0 & 12.0 & 42.75 \\
\hline \multirow{3}{*}{$\begin{array}{l}\text { Economics and } \\
\text { marketing }\end{array}$} & Economics & 12.0 & 9.0 & 5.0 & 12.0 & 38.0 \\
\hline & Traditional marketing & 10.5 & 9.0 & 5.0 & 12.0 & 36.5 \\
\hline & Digital marketing & 15.5 & 9.0 & 6.0 & 12.0 & 42.5 \\
\hline \multicolumn{2}{|c|}{ Average time per module } & 11.31 & 8.48 & 6.43 & 12.1 & 38.31 \\
\hline \multicolumn{2}{|l|}{ Total time } & 268.75 & 178.0 & 135.0 & 254.0 & 835.75 \\
\hline
\end{tabular}

${ }^{2}$ Subject shows main categories covered in the online modules.

'Subcategory shows the subtopics covered in individual learning modules ( $\approx 60 \mathrm{~min}$ each $)$.

${ }^{x}$ Research/content development includes time for searching, reading, and summarizing pertinent literature on each subject to develop content.

"PointPoint development includes time needed to develop an outline and individual slide text for each module.

'Image organization includes time needed to search for images, edit, and insert into PowerPoint files.

uScript/quiz development includes developing text for narration.

${ }^{\mathrm{t}} \mathrm{NA}=$ not applicable.

${ }^{\mathrm{s}} \mathrm{ANLA}=$ American Nursery and Landscape Association (Washington, DC).

development. Toward the end of the content development, the final storyboard format was developed. The final format eliminated excessive text and refined the text remaining on each slide, eliminated use of multiple photos per slide, and all photos were made a uniform size (see Technology section). At this time, key words or phrases on each slide were bolded for emphasis.

After module scripts were finalized, they were read aloud by a narrator and recorded using a headset. In some cases, the narrator used a rapid rate of speech that was not conducive to learner comprehension. In these situations, the e-learning systems designer used Audacity ${ }^{\circledR}$ (Audacity Team, 2016) to digitally reduce the narration speed. Editing and fine-tuning sound quality of audio files requires expertise and is time consuming.
The final step in program development before rendering (merging audio with slides and publishing online) was quality control. The e-learning systems designer, project coordinator, or curriculum developer double checked the technical content of each module for accuracy and to ensure consistent formatting. Then the modules were rendered and uploaded into Moodle ${ }^{\mathrm{TM}}$ (Moodle, Perth, Australia) as a web-ready version. Before launch, the program was tested by the project coordinator and a small test group consisting of three people. This was done to ensure all content displayed correctly, that the user could progress through the course as intended, and the conditional permissions system was working properly. The time required for the test group to pilot the program is not reported in the tables.
Technology. PowerPoint slides (images and bulleted text) were used to develop the primary framework of each module while the script was first drafted using Word (Microsoft Corp.). In the first draft of each module, images were selected and inserted into PowerPoint slides. To be compatible with Moodle ${ }^{T M}$ and to maintain a uniform load time throughout each module, a single image was selected for each slide and was edited to be the same size $[288 \times 384$ pixels at 96 dots per inch (dpi)] using Fireworks $^{\circledR}$ (Adobe Systems, San Jose, CA). This program was chosen for its automated (batch) image editing features, although other programs can be used to edit image size manually. After PowerPoint development, the script was developed.

After the modules were built in PowerPoint, the e-learning systems 
Table 2. Time needed to convert PowerPoint (Microsoft Corp., Redmond, WA) slides into storyboard template, perform quality control checks, and narrate Tennessee Master Nursery Producer modules.

\begin{tabular}{|c|c|c|c|c|c|c|c|c|c|}
\hline \multirow[b]{3}{*}{ Subject ${ }^{\mathrm{z}}$} & \multirow[b]{3}{*}{ Subcategory ${ }^{\mathrm{y}}$} & \multicolumn{5}{|c|}{ Conversion to storyboard template } & \multirow[b]{2}{*}{ Narration $^{\mathrm{s}}$} & \multirow[b]{2}{*}{$\begin{array}{l}\text { Quality } \\
\text { control }\end{array}$} & \multirow[b]{2}{*}{$\begin{array}{l}\text { Total } \\
\text { time }\end{array}$} \\
\hline & & $\begin{array}{l}\text { Storyboard } \\
\text { conversion }^{\mathrm{x}}\end{array}$ & $\begin{array}{l}\text { Image } \\
\text { edits }\end{array}$ & $\begin{array}{l}\text { Script/quiz } \\
\text { conversion }^{v}\end{array}$ & Fine-tuning ${ }^{\mathrm{u}}$ & $\begin{array}{c}\text { Total conversion } \\
\text { time }^{t}\end{array}$ & & & \\
\hline & & \multicolumn{8}{|c|}{ Time (h) } \\
\hline All & $\begin{array}{l}\text { General narration } \\
\text { coordination, } \\
\text { narration } \\
\text { corrections }\end{array}$ & $\mathrm{NA}^{\mathrm{P}}$ & $\mathrm{NA}$ & NA & $\mathrm{NA}$ & $\mathrm{NA}$ & 8.6 & NA & 8.6 \\
\hline \multirow{4}{*}{$\begin{array}{l}\text { Container } \\
\text { production }\end{array}$} & General facilities & 0.0 & 0.0 & 0.0 & 4.0 & 4.0 & 6.7 & 6.0 & 16.7 \\
\hline & Overwintering & 1.3 & 1.5 & 0.5 & 6.3 & 9.5 & 7.1 & 5.5 & 22.1 \\
\hline & Substrate components & 1.0 & 1.0 & 0.5 & 6.3 & 8.8 & 6.8 & 6.0 & 21.5 \\
\hline & $\begin{array}{l}\text { Substrate properties } \\
\text { and floor } \\
\text { management }\end{array}$ & 1.0 & 1.0 & 0.5 & 5.3 & 7.8 & 6.9 & 6.3 & 20.9 \\
\hline \multirow{3}{*}{$\begin{array}{l}\text { Field } \\
\text { production }\end{array}$} & General facilities & 1.0 & 1.0 & 1.0 & 6.5 & 9.5 & 6.8 & 7.8 & 24.1 \\
\hline & $\begin{array}{l}\text { Layout; cover crops; } \\
\text { planting }\end{array}$ & 1.0 & 1.0 & 1.0 & 5.0 & 8.0 & 6.9 & 6.8 & 21.7 \\
\hline & $\begin{array}{l}\text { ANLA }^{\circ} \text { standards; } \\
\text { harvesting }\end{array}$ & 1.0 & 1.0 & 0.5 & 6.3 & 8.8 & 6.9 & 6.5 & 22.2 \\
\hline \multirow{5}{*}{$\begin{array}{l}\text { Pest } \\
\text { management }\end{array}$} & Weed control & 2.0 & 2.0 & 1.0 & 4.5 & 9.5 & 7.5 & 8.0 & 25.0 \\
\hline & Insect control & 1.5 & 2.0 & 1.5 & 6.1 & 11.1 & 7.4 & 6.8 & 25.2 \\
\hline & Regulations & 2.0 & 3.0 & 1.5 & 8.0 & 14.5 & 7.2 & 5.2 & 26.8 \\
\hline & $\begin{array}{l}\text { Disease } \\
\text { identification }\end{array}$ & 1.0 & 2.0 & 1.0 & 6.3 & 10.3 & 7.1 & 6.7 & 24.0 \\
\hline & $\begin{array}{l}\text { Disease } \\
\text { management }\end{array}$ & 1.0 & 2.0 & 1.0 & 9.5 & 13.5 & 7.0 & 6.0 & 26.5 \\
\hline Plant nutrition & $\begin{array}{l}\text { Plant nutrition and } \\
\text { fertilizer }\end{array}$ & 1.5 & 2.0 & 0.8 & 7.8 & 12.0 & 7.3 & 8.4 & 27.7 \\
\hline \multirow{2}{*}{ Irrigation } & Delivery; scheduling & 1.0 & 2.3 & 0.8 & 6.0 & 10.0 & 7.1 & 8.3 & 25.4 \\
\hline & $\begin{array}{l}\text { Capturing and } \\
\text { reusing }\end{array}$ & 1.0 & 1.0 & 0.5 & 5.5 & 8.0 & 7.1 & 7.3 & 22.4 \\
\hline Pruning & Pruning & 1.0 & 1.3 & 0.5 & 4.8 & 7.5 & 7.1 & 7.6 & 22.2 \\
\hline \multirow[t]{2}{*}{ Propagation } & Seed & 1.0 & 1.0 & 0.5 & 7.3 & 9.8 & 6.9 & 7.0 & 23.7 \\
\hline & Vegetative & 1.0 & 1.0 & 0.5 & 5.5 & 8.0 & 6.9 & 8.0 & 22.9 \\
\hline \multirow{3}{*}{$\begin{array}{l}\text { Economics and } \\
\text { marketing }\end{array}$} & Economics & 1.5 & 1.0 & 1.0 & 4.5 & 8.0 & 7.2 & 6.4 & 21.6 \\
\hline & $\begin{array}{l}\text { Traditional } \\
\text { marketing }\end{array}$ & 1.0 & 1.0 & 1.0 & 5.3 & 8.3 & 7.0 & 6.7 & 21.9 \\
\hline & Digital marketing & 1.0 & 1.0 & 1.0 & 6.3 & 9.3 & 7.0 & 7.3 & 23.5 \\
\hline \multicolumn{2}{|c|}{ Average time per module } & 1.1 & 1.4 & 0.8 & 6.0 & 9.3 & 7.0 & 6.9 & 23.2 \\
\hline \multicolumn{2}{|l|}{ Total time } & 23.75 & 29.0 & 16.5 & 126.7 & 195.9 & 156.4 & 144.2 & 496.5 \\
\hline
\end{tabular}

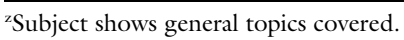

y Subcategory shows the topics covered in individual learning modules $(\approx 60$ min each $)$.

${ }^{x}$ Storyboard coversion includes time needed to edit text from original PowerPoint slides into final storyboard format.

"Image edits includes selecting images, editing size, and inserting images into storyboard template [developed using Moodle ${ }^{\mathrm{TM}}$ software (Moodle, Perth, Australia)].

'Script/quiz conversion includes time needed to copy, paste, and edit script and quiz text into the storyboard template.

"Fine-tuning includes bolding text in each slide for emphasis, formatting, and editing.

${ }^{t}$ Total conversion time $=$ sum of storyboard conversion + image edits + script $/$ quiz conversion + fine-tuning .

${ }^{s}$ Narration incudes time needed to record audio and edit for each module.

${ }^{\mathrm{r}}$ Quality control includes time needed to review each module and correct errors missed during initial proofreading.

${ }^{\mathrm{q}}$ Total time $=$ sum of total conversion time + narration + quality control.

PNA = not applicable.

${ }^{\circ}$ ANLA = American Nursery and Landscape Association (Washington, DC).

designer published the modules into the final learning module format using Presenter (Articulate ${ }^{\circledR}$, New York, NY), a software package designed to add interactivity, branching, multimedia, and narration to PowerPoint content. Narration files were created outside of PowerPoint to allow for greater flexibility in current and future multimedia development.
An open-source audio editor, Audacity ${ }^{\circledR}$, was used for narration. After narration files were created in Audacity ${ }^{\circledR}$, they were imported into Articulate Presenter.

The TMNP required a series of conditional completions controlling progress including a passing score on the current module's quiz to access the subsequent module's content, a sequencing of program content (completing modules in order), and a number of questionnaires that were needed for program review by the project team. For these reasons, Moodle ${ }^{\mathrm{TM}}$ was selected as the learning platform. Moodle ${ }^{\mathrm{TM}}$ hosting was handled by third-party application service providers under contract agreements with the University of 
Tennessee Extension Service. In addition, the current web server for Moodle ${ }^{\mathrm{TM}}$ is capable of handling up to 200 concurrent users.

\section{Results}

The cost of developing an online extension program will be highly dependent upon on the infrastructure at a given institution, including software and licensing agreements, as well as the availability and quality of IT technical services and web servers. Software costs for the TMNP were minimized by using open-source software, Moodle $\mathrm{T}^{\mathrm{TM}}$ and Audacity ${ }^{\circledR}$. Articulate ${ }^{\circledR}$ Presenter and Microsoft ${ }^{\circledR}$ Office (PowerPoint and Word), are avilable for $\$ 800$ and $\$ 140$, respectively, with an educational discount. Fireworks is available as an annual license for $\approx \$ 35 /$ month, but open-source programs could be used.

The time required to complete each module, including the initial development (PowerPoint file and script) by the curriculum developer and technical editing by the project coordinator is included in Table 1. Initial research/content development ranged from 7.5 to $17.25 \mathrm{~h}$, primarily depending on the content developer's expertise. For example, the area in which the developer had the most experience (weed control), content was developed in $7.5 \mathrm{~h}$, but in an area in which the developer had less experience (pruning) it took significantly longer $(17.25 \mathrm{~h})$.

The disparity in development time existed, although subject matter experts provided base presentations for some modules (PowerPoint files developed for live audiences). Presentations developed for live audiences had to be significantly modified for web delivery, not only adapting the content to the storyboard template but also developing the script and quiz questions. Moreover, literature searches were necessary to expound upon slides containing minimal text or explanation. In other cases, content took longer to develop due to lack of published literature or images of suitable quality, composition, or content.

PowerPoint development was generally a straightforward process and required 8 to $10 \mathrm{~h}$, regardless of subject matter (Table 1 ). The time needed to select, organize, and insert images into the PowerPoint file ranged from 5 to $10 \mathrm{~h}$ per module and decreased as familiarity with the image library increased. Time needed to sort through and select images generally decreased over time as the content developer became more familiar with the image library. Finding and editing images to meet pedagodical objectives and IT requirements is known to be time consuming (Zobrist, 2014), and was 16\% of the initial module development time (Table 1). Similar to PowerPoint development, scripts and quizzes were relatively straightforward to prepare, requiring $\approx 12 \mathrm{~h}$ to complete per module.

Achieving the final format required a significant amount of time, on average $9.3 \mathrm{~h}$ per module (total conversion time of $195.9 \mathrm{~h}$ for 21 modules) (Table 2), and was completed by the three key personnel. This time was predominately spent converting PowerPoint files into the final template, editing images and image size (as noted), and "finetuning" which consisted of bolding text for emphasis, selective use of red font color to signify a caution, and ensuring that script text was in the same order and identical or nearly identical verbiage as slide bullet points.

For every $\mathrm{h}$ of narration audio (i.e., narration for one module), $\approx 6 \mathrm{~h}$ were required to edit the narration and sync audio with bullet point animation (Table 2). Using a professional narrator and preparing concise scripts can reduce the time spent narrating and editing audio files. Vocabulary and sentence structure affect how efficiently the script can be narrated. Shorter, direct, and simple sentences should be used rather than longer, complex, or wordy sentences. Use of semicolons can be distracting and parenthetical comments should be avoided. In the case of the TMNP, one of the two narrators had a strong knowledge base of the content and terminology being presented; however, if the narrator does not have this knowledge, phonetic pronunciation of foreign or unfamiliar words may be needed or a subject matter expert may need to accompany the narrator during recording sessions. Reviewing the web-ready version for quality control required $\approx 2$ h (i.e., double

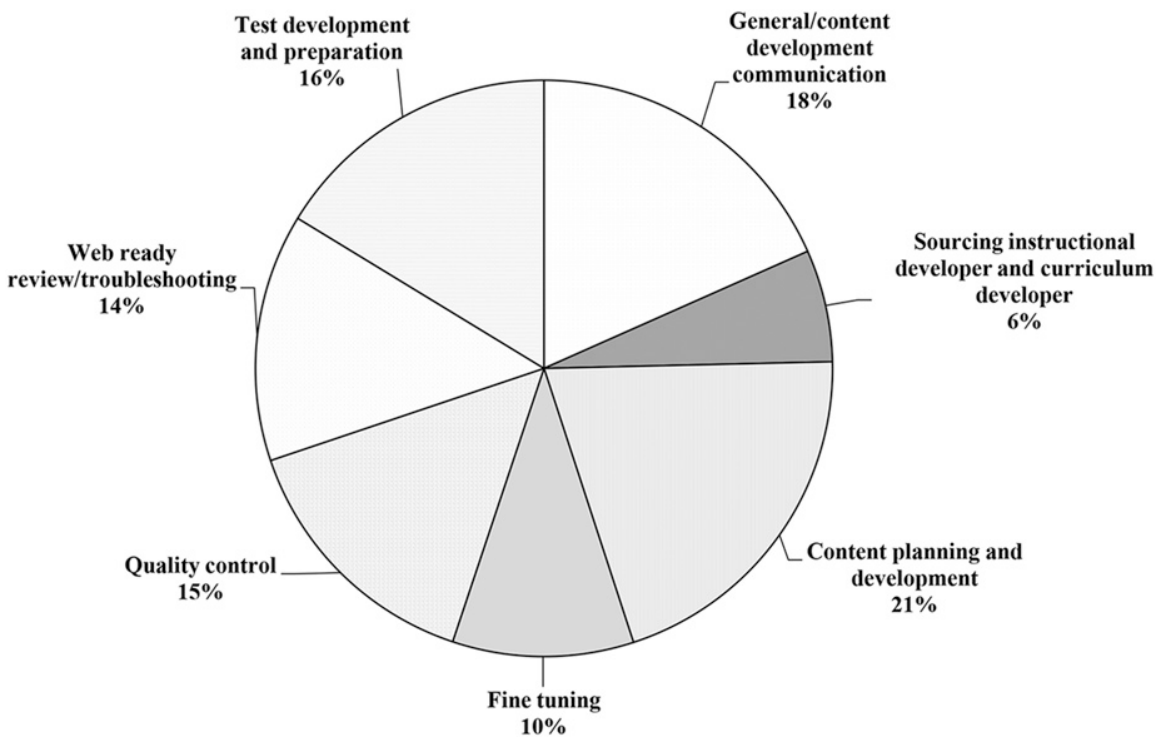

Fig. 2. Project coordinator's time (h) breakdown by percentage of total time $(473 \mathrm{~h})$. Test development and preparation $=$ time needed to test the program and evaluate potential online learning platforms; general and content development = time taken to review material and discuss course content with curriculum developer; sourcing instructional and curriculum developer $=$ time needed to find / hire personnel; content planning and development = time needed to plan, prepare, and develop the final draft course content; fine-tuning = time needed to review, revise, and edit modules for emphasis (e.g., bold or colored font), once completed; quality control $=$ time needed to review each module and correct any errors missed during initial proofreading; web-ready review and troubleshooting = time needed to view modules in online format and repair any problems with functionality. 
the length of the module), with additional time spent addressing issues found in the review and uploading process; as a result, an average of $6.9 \mathrm{~h}$ of quality control work was required per module.

The true cost of developing a program similar to the TMNP must account for faculty and staff time embedded in the project, work contracted to outside professionals or funded by external sources, and the opportunity cost of other projects not pursued. The largest single financial cost during the development of the TMNP was personnel, including the embedded cost of the project coordinator $(473 \mathrm{~h})$ and e-learning specialist $(40 \mathrm{l} \mathrm{h})$ who were paid from institutional funds and the curriculum developer $(847 \mathrm{~h})$ and primary narrator $(32 \mathrm{~h})$, who were paid on grant funds in support of the TMNP (Tables 1 and 2; Figs. 2-4). The average time needed to prepare each module was $61.5 \mathrm{~h}[38.3 \mathrm{~h}$ (Table 1) plus $23.2 \mathrm{~h}$ (Table 2)]. Completing the project including administration and coordination, required $172 \mathrm{l} \mathrm{h}$ of labor or $81.9 \mathrm{~h}$ per module (Figs. 2-4). At a hypothetical $\$ 30$ per hour labor rate and 35\% benefits rate, the labor cost for 1721 h would be $\$ 69,700.50$ which is comparable to published costs $(\$ 70,000)$ of developing online college courses (Boettcher, 2004). Initial development and online publication will probably be the highest overall cost of a similar program, but recurring costs will also be encountered. Content will need to be updated periodically and web servers will need to be maintained throughout the life of the program. Participants are also likely to have additional questions that will need to be answered, and may encounter errors or technical glitches that will need to be corrected.

\section{Discussion}

One of the most important steps in developing extension curricula is selection of course material. The TMNP was successfully completed due to the personnel involved, their familiarity with the industry in the state, and knowledge of issues that needed to be addressed. An important consideration when forming a committee is the area in which each member concentrates their professional activities. It is ideal to have an interdisciplinary team as a resource for the curriculum developer so that each subject covered can consist of the most up-to-date information available, current research projects can be featured when appropriate; and so editing and quality control are performed by individuals with expertise specific to that topic. This consideration may not be necessary if the online course focuses on one subject or a narrow field.

When creating an asynchronous online course, the biggest challenge is often that a significant amount of time will be needed to create or revise content to make it suitable for online delivery (Zobrist, 2014). Curriculum previously designed for live presentations is not adequate for online delivery. Although reading the text on slides for a live presentation is discouraged, in asynchronous learning modules, bullet points and narration need to be identical or nearly so and graphics must be carefully selected to clearly illustrate the teaching points without an instructor present to highlight or explain photos, diagrams, or charts (Qayyum and Eastman, 2006). Second, each module or class session must be formatted consistently and clearly presented, as pedagogy is more important in an asynchronous learning environment (Bernard et al., 2004), since there is no opportunity for students to spontaneously request and receive immediate clarification (students did have the opportunity to call or e-mail the program coordinator with questions).

For the TMNP, the content developer and e-learning specialist were responsible for creating and revising content and preparing it for online delivery; however, dividing content

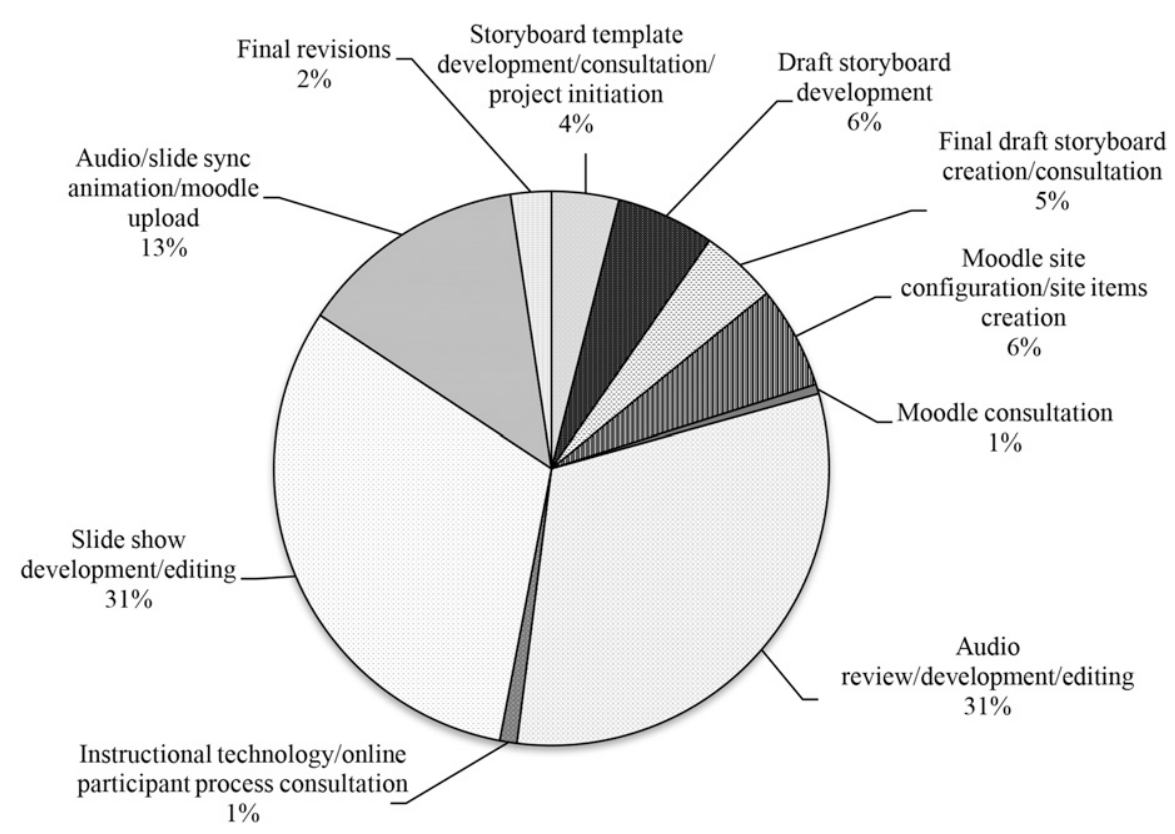

Fig. 3. e-learning systems designer (information technologist) time (h) breakdown by percentage of total time $(401 \mathrm{~h})$. Audio/slide sync animation/SCORM Publish/Moodle (Moodle, Perth, Australia) upload = time needed to publish final content online; final revisions = time needed to make minor adjustments once modules were published online and complete; storyboard template development/ consultation/project initiation $=$ time needed to discuss project with coordinator and choose program requirements, conditions, and appearance; draft storyboard development = time needed to develop module templates; final draft storyboard creation/consultation = time needed to end template; Moodle site configuration / site items creation $=$ time needed to configure Moodle site to meet system requirements; Moodle consultation = time consulting on Moodle platform with project coordinator; audio review/development/editing = reviewing and editing narration audio files and syncing with slides; instruction technolology/online participant process consultation $=$ providing technical assistance to course participants; slideshow development/editing = developing PowerPoint (Microsoft Corp., Redmond, WA) slides and templates that were uploaded onto the Moodle platform. 


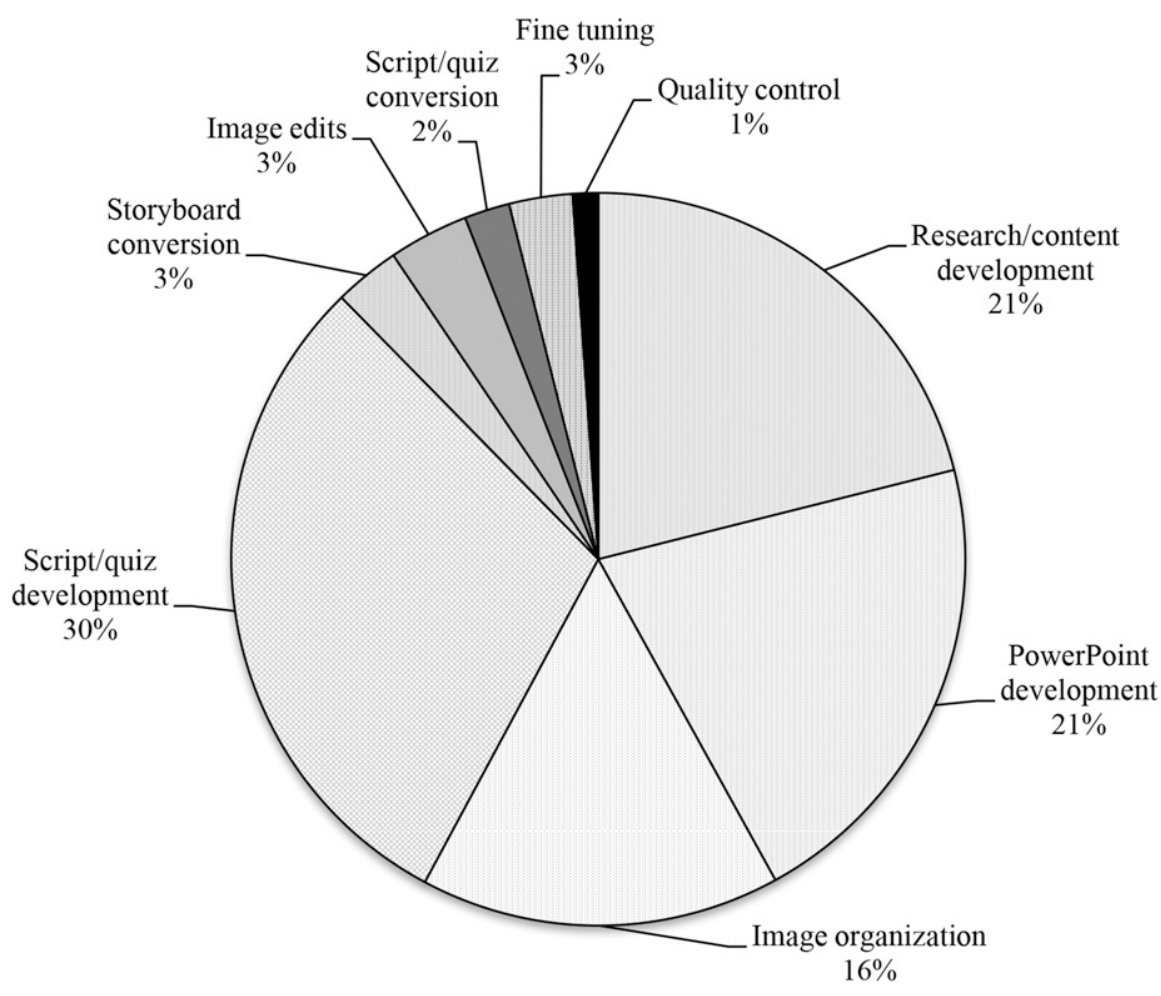

Fig. 4. Curriculum developer time (h) breakdown by percentage of total time $(847 \mathrm{~h})$. Image edits = time needed to select images, edit size, and inserting images into storyboard templates; script/quiz conversion = time needed to copy, paste, and edit script and quiz into storyboard template; fine-tuning = includes bolding text for emphasis, formatting, and editing; quality control = time to review each module and correct errors missed during final proofreading; research/content development $=$ time needed to search, read, and summarize pertinent literature on each subject to develop content; PowerPoint (Microsoft Corp., Redmond, WA) development $=$ time needed to develop an outline and individual slide text for each module; image organization $=$ time needed to search for images, edit, and insert into PowerPoint slides; script/quiz development = includes time needed to develop text for narration; storyboard conversion = time needed to edit text from original PowerPoint slides into final storyboard template.

among different faculty may be necessary if budgets are limited. This approach may present challenges including scheduling conflicts and other faculty obligations which could delay course development. If content development must be split among several different people, a single format must be agreed upon initially and a clear production schedule must be established from the beginning. The downside of not using individual faculty members is that course content could potentially be enhanced by their individual area of expertise, whereas one individual will not possess the same level of in-depth knowledge.

When developing curriculum that is divided into categories and subcategories, the order of completion (i.e., preset order or participants choose the order) must be determined during the content development stage as this may affect the content or background information needed for each module. If modules are designed to be stand-alone, some background may be needed or repeated for different subjects in each module, whereas if the course is designed to be completed in a predetermined, fixed order, this background information may not be necessary. For example, if participants are able to view a disease management module before a disease identification course, some disease identification information would be needed in the disease management module. There are advantages and disadvantages to each method. Designing standalone modules allows participants to view the module with most useful or needed information at any one time, but this may require additional time and planning in the course developmental stages, and could limit the overall amount of material covered due to time and financial limitations.

When initiating an asynchronous online program, it is essential that all members of the development team have clearly defined roles and that everyone involved in the project has an understanding of the requirements of the online program. The more familiar the e-learning system designer is with the audience (e.g., computer literacy) and the final outcomes of the online program (appearance, functionality, educational objectives, etc.), the better the overall results will be. It is also important to establish a schedule for completion of each section of the curriculum and allow time for unforeseen changes to the curriculum such as from an emerging pest or regulatory change. To keep developmental costs as low as possible and minimize development time, it is critical to establish the format at the beginning of the development process, including image size and placement, font, slide, or page organization, and any other use of graphics or design to avoid reformatting. Images should be well organized into a central location and clearly labeled. All content used to develop the curriculum should be saved in a central location with sources clearly identified for future reference and fact checking. Utilization of high-quality open-source software when applicable will also help reduce program developmental costs associated with software purchases. Developing similar programs will likely require a significant time commitment and resources initially; however, these programs can provide grower convenience and access to consistent, high-quality curriculum while offering extension professionals greater flexibility and the ability to impact a wider audience over the long term.

\section{Literature cited}

Allen, A.E. and J. Seaman. 2011. Going the distance: Online education in the United States. 28 Dec. 2015. <http:// www.onlinelearningsurvey.com/ reports/goingthedistance.pdf>.

Allred, S.B. and P.J. Smallidge. 2010. An educational evaluation of web-based forestry education. J. Ext. 48(6):6FEA2. 
28 Dec. 2015. <http://www.joe.org/ joe/2010december/a2.php>.

Audacity Team. 2016. Audacity free audio editor and recorder. Version 2.1.2. 3 Mar. 2016. <http://www.audacityteam. org $>$.

Bean, C. 2014. The accidental instructional developer. 1st ed. Assn. Talent Development, Alexandria, VA.

Bernard, R.M., P.C. Abrami, Y. Lou, E. Borokhovski, A. Wade, L. Wozney, P.A. Wallet, M. Fiset, and B. Huang. 2004. How does distance education compare with classroom instruction? A meta-analysis of the empirical literature. Rev. Educ. Res. 74:379-439.

Boettcher, J. 2004. Online course development: What does it cost? 7 Mar. 2016. <http://www.immagic.com/ eLibrary /ARCHIVES/GENERAL/ CMPSTECH/C040629B.pdf>.

Dittman Research and Communications Corp. 2010. Public awareness, opinion, and perceptions of UAF Cooperative $\mathrm{Ex}^{-}$ tension Service. 28 Dec. 2015. <https:// www.uaf.edu/files/ces/about/strategic/ Dittman-poll.pdf $>$.

Fulcher, A., S.C. Marble, W. McCall, W. Yeary, and R. Karel. 2014. Tennessee Master Nursery Producer. 7 Mar. 2016. <https://extol.tennessee.edu/people/ course $/$ index.php? categoryid $=35>$.

Haynie, D. 2015. Study shows sluggish online learning growth for second year.
28 Dec. 2015. <http://www.usnews. com/education/online-education/ articles $/ 2015 / 02 / 05 /$ study-showssluggish-online-learning-growth-forsecond-year?page $=2>$.

Herreid, C.F. and N.A. Schiller. 2013. Case studies and the flipped classroom. J. Coll. Sci. Teach. 42:62-66.

Jones, R., A. Goheen, K. Dhuyvetter, T. Kastens, and V. Amanor-Boadu. 2007. Using distance education in extension programming. J. Agr. Appl. Econ. 39:265-274.

Marble, S.C., A. Fulcher, and J. Toman. 2016. Advantages and disadvantages of asynchronous online extension programming for delivering master producer content. HortTechnology 26:584-587.

Qayyum, A. and B. Eastman. 2006. Knowledge is PowerPoint: Slideware in e-learning, p. 335-349. In: M. Bullen and D. Janes (eds.). Making the transition to e-learning: Strategies and issues. Idea Group, Hershey, PA.

Rich, S.R., S. Komar, B. Schilling, S.R. Tomas, J. Carleo, and S.J. Colucci. 2011. Meeting extension programming needs with technology: A case study of agritourism webinars. J. Ext. 49(6):6FEA4. 28 Dec. 2015. <www.joe.org/joe/2011december/ a4.php>

Sagor, E.S., A.M. Kueper, C.R. Blinn, and D.R. Becker. 2014. Extension forestry in the United States: A national review of state-level programs. J. For. 112:15-22.

Tennessee Department of Agriculture. 2015. Tennessee Agricultural Enhancement Program. 28 Dec. 2015. <http://www.tn.gov/ agriculture/topic/ag-farms-enhancement>.

The Economist. 2014. The future of universities: The digital degree. 8 Mar. 2016. <http://www.economist.com/ news/briefing/21605899-staid-highereducation-business-about-experiencewelcome-earthquake-digital $>$.

VanDerZanden, A.M. 2013a. A webinar series to provide advanced training for Iowa nursery and landscape professionals. HortScience 48:S415 (abstr.).

VanDerZanden, A.M. 2013b. Asynchronous continuing education for Iowa's green industry professionals. HortTechnology 23:677-682.

Vergot, P., H. Kent, and L. Jackson. 2014. Extension the next 100 years: Using emerging communication technologies to deliver international extension programs. 7 Mar. 2016. <http://journals.sfu.ca/ cigrp/index.php/Proc/article/viewFile/ $160 / 159>$.

Zobrist, K.W. 2014. Developing a successful asynchronous online extension program for forest landowners. J. Ext. 52(2):2IAW2. 28 Dec. 2015. <http:// www.joe.org/joe/2014april/iw 2 . php>. 